\title{
To stay or to go: voluntary survivor turnover following an organizational downsizing
}

\author{
GRETCHEN M. SPREITZER ${ }^{1 *}$ AND ANEIL K. MISHRA ${ }^{2}$ \\ ${ }^{1}$ School of Business, The University of Michigan, Ann Arbor, U.S.A. \\ ${ }^{2}$ Charles H. Babcock Graduate School of Management, Wake Forest University, Winston-Salem, U.S.A.
}

Summary

\begin{abstract}
This paper examines the relationship between survivor reactions to a downsizing and retention subsequent to a downsizing. We hypothesize that survivors who experience the downsizing as distributively, procedurally, and interactionally just and who see top management as trustworthy will feel more attached to the organization because each reduces the threat inherent in downsizing. In addition, we hypothesize that survivors who feel empowered will also feel more attached to the organization because they feel better able to cope with the downsizing. We further hypothesize that those survivors who feel more attached to the organization following the downsizing will be more likely to remain with the organization in the coming year. The theoretical model is tested on a sample of aerospace employees who survived an organizational downsizing. The trustworthiness of management, distributive justice, procedural justice, and three dimensions of empowerment are found to facilitate more organizational attachment. Higher levels of attachment are found, in turn, to facilitate less voluntary turnover in the year following the downsizing. Copyright (C) 2002 John Wiley \& Sons, Ltd.
\end{abstract}

\section{Introduction}

Downsizing is defined as a purposeful reduction in the size of an organization's workforce (Cascio, 1993). Prior research has shown that downsizing can have profound effects on survivors' (i.e., those who remain employed subsequent to downsizing) behavior including, for example, job involvement (Allen, Freeman, Russell, Reizenstein, \& Rentz, 2001; Brockner, Grover, \& Blonder, 1988), good citizenship behavior (Bies, Martin, \& Brockner, 1993), withdrawal (Brockner, 1990), work effort (Brockner, Grover, Reed, \& DeWitt, 1992) and productivity (Brockner, Davy, \& Carter, 1985). While we know quite a bit about survivors' immediate reactions to a downsizing, we have only a limited understanding of survivors' longer-term behavioral responses, particularly in terms of survivors' willingness to remain with the firm subsequent to the downsizing.

Evidence suggests that an organizational downsizing, whether or not one's job security is threatened, deeply affects the attachment survivors feel toward the organization (Brockner, Tyler, \&

* Correspondence to: Gretchen M. Spreitzer, School of Business, Room A2144, The University of Michigan, 701 Tappan Street, Ann Arbor, MI 48109-1234, U.S.A. E-mail: spreitze@umich.edu 
Cooper-Schneider, 1992; Brockner, Wiesenfeld, Reed, Grover, \& Martin, 1993; Brockner, Grover, Reed, DeWitt, \& O’Malley, 1987). Surviving employees may perceive that the organization is not committed to them, thereby reducing their willingness to remain with the organization (Niehoff, Moorman, Blakely, \& Fuller, 2001). A reduction in organizational attachment is also a powerful determinant of voluntary turnover (Mitchell \& Lee, 2001).

In this paper, we examine the effects of organizational downsizing on survivor rates of voluntary turnover one year subsequent to the organizational downsizing. Our aim is to examine how survivors' experience of a firm's downsizing will influence their decision to remain with the organization in the year subsequent to the downsizing. Drawing on Mishra and Spreitzer's (1998) stress-based model of survivor responses to downsizing, we develop specific hypotheses about the roles of trust, justice, and empowerment in preserving survivors' attachment to the organization and in turn how that attachment will increase the likelihood that they will remain with the organization in the year subsequent to the downsizing. We then describe our research design, discuss our results, and provide some implications of the research.

\section{Motivation for the Research}

This research has the capacity to contribute to research on voluntary turnover. Only one study has looked specifically at voluntary turnover in a downsizing context. It found that the main effects of being younger, being white collar, and having a predisposition to leave were significant in predicting subsequent voluntary resignations (Iverson \& Pullman, 2000). This research, however, did not go beyond demographics to look specifically at how survivors experienced the downsizing as a predictor of voluntary turnover.

We believe that the context of downsizing will be particularly salient for understanding individuals' psychological attachments and subsequent voluntary turnover. Downsizing is likely to be experienced as a 'shock' to employees, jarring them 'toward deliberate judgments about their jobs,' particularly in deciding whether to stay or leave the organization (Lee \& Mitchell, 1994: 60). Moreover, the downsizing may be experienced as a violation of the psychological contract (Robinson \& Rousseau, 1994; Rousseau, 1995), making survivors more susceptible to voluntary turnover than employees in a more stable work environment. At a minimum, survivors are likely to experience significant changes in their context following a downsizing, including possibly new job responsibilities and reporting relationships, changes in processes and procedures, and the loss of colleagues (Allen et al., 2001). Thus, it is critical to better understand how survivors' experiences of the context of the downsizing influence their attachment and retention.

This research also has the potential to contribute to the literature on downsizing. First, more and more organizational behavior theories are exploring the impact of 'active' personal control from different angles in a workplace context. Examples include personal initiative (Frese \& Fay, 2001), voice (Van Dyne \& LePine, 1998), taking charge (Morrison \& Phelps, 1999), proactive coping (Aspinwall \& Taylor, 1997), and empowerment (Spreitzer, 1995). While empirical research on downsizing has looked carefully at the roles of trust and justice in understanding survivors' responses, it has largely ignored the role that a sense of personal control plays in predicting survivor reactions to downsizing. But we know that under conditions of change or stress, beliefs about personal control are powerful influences on individual coping and strain. For example, work demands can be increased with minimal threat to individuals as long as personal control is simultaneously enhanced (Parker \& Spriggs, 1999). Thus, in our theoretical framework, we examine one manifestation of personal control - survivor feelings of psychological empowerment. We focus on survivor empowerment rather than personal control 
more generally because empowerment was a key component in Mishra and Spreitzer's (1998) theoretical framework of survivor's responses to downsizing.

A second way that we may contribute to the downsizing literature is that much of downsizing research has been conducted in a laboratory setting or modelled as a single post-event phenomenon. Our research moves beyond a purely cross-sectional research design to examine a critical behavior that comes at a later point in time-it is field-based and longitudinal.

This research also has the potential to contribute to the practice of downsizing. The issue of survivor retention subsequent to the downsizing is a major concern to companies trying to rejuvenate themselves following a downsizing. There remains substantial competition among employers for skilled workers. Declining employee loyalty has led individuals to more readily change employers for better salaries, improved working conditions, and increased responsibility (Reichheld, 2001). More importantly, prior research has suggested that high potential employees have many alternative job opportunities and may be most tempted to leave for a more stable work environment following a downsizing (Mishra, Spreitzer, \& Mishra, 1998). Given that organizations invest considerable money and time into hiring and training employees, management should be interested in better understanding how to safeguard their investment. Thus, the need to retain survivors with valuable skills becomes an important issue for downsizing firms. We now turn to an introduction of our theoretical framework.

\section{Theoretical Framework}

Prior research has shown that employees' experience in the organization, as reflected in attitudes such as job satisfaction and commitment, is an important predictor of voluntary turnover (Cohen, 1993; Cohen \& Hudecek, 1993; Hom, Caranikas-Walker, Prussia, \& Griffeth, 1992; Hom, Griffeth, \& Sellaro, 1984; Lee \& Mowday, 1987; Mobley, 1977; Somers, 1995; Tett \& Meyer, 1993). The Unfolding Model of Voluntary Turnover (Mitchell \& Lee, 2001) has received significant attention in the turnover literature. This model suggests that the great majority of those who voluntarily leave their jobs do so in response to a shock to the system. A shock is any expected or unexpected change to an ongoing social system that shakes an employee out of a steady state with respect to his or her thinking about the job and organization. The shock causes the person to pause and think about the meaning or implication of the event in relation to his or her job. In this paper, we examine the effects of one specific kind of shock - an organizational downsizing. We build on the unfolding model in suggesting that the experience survivors have during the organization downsizing will shape their willingness to remain with the organization in the years subsequent to the downsizing.

The Mitchell and Lee (2001) model suggests that a construct called job embeddedness will play a critical role in the attachment and subsequent willingness to remain with an organization following some kind of shock. When individuals are embedded or immersed in their jobs, they are attached in various ways, including: (1) 'links' (i.e., formal or informal connections either on or off the job-such as organizational tenure and roots in the community); (2) 'fit' (i.e., individuals' compatibility or congruence with their work and non-work settings - such as their fit with the organizational culture and attraction to the community where one lives); and (3) 'sacrifice' (i.e., perceived loss of material or psychological benefits - from work (including things like having autonomy or great job perks) or from the community (a short commute). The content of the connection or attaching factors can vary substantially based on the situation at hand. In the context of a downsizing shock, we believe that several elements related to the notion of embeddedness will be particularly relevant for survivors as they assess their willingness to voluntarily remain with the organization. While in our empirical analyses 
we control for job embeddedness 'links' to the community (e.g., spouse working outside of home, dependent children) and to the organization (e.g., tenure), our theoretical framework captures several additional job embeddedness components as important predictors of survivor attachment and subsequent voluntary turnover.

\section{Predictors of survivor attachment}

We draw on Mishra and Spreitzer's (1998) model of survivor responses to downsizing, which builds on Lazarus and Folkman's (1984) theory of stress, in forming our hypotheses regarding predictors of survivor attachment. Brockner and Wiesenfeld (1992) have also applied this theory of stress to understanding survivor responses to downsizing. We posit that the trustworthiness of top management and perceived justice of the downsizing implementation will lead to more survivor attachment because they reduce perceptions of threat inherent in the downsizing. Trust reflects part of the 'organization fit' dimension of Mitchell and Lee's (2001: 221) job embeddedness (as captured in their idea about feeling personally valued). Justice reflects part of the 'organization sacrifice' dimension of Mitchell and Lee's (2001: 221) job embeddedness (as captured in their idea about feeling respected). We also posit that survivor empowerment will also lead to more attachment as it increases survivors' sense that they have the capability to cope with the downsizing. Empowerment reflects part of the 'organization sacrifice' dimension of Mitchell and Lee's (2001) job embeddedness (as captured in their idea about having freedom to do one's job). Our basic theoretical framework is illustrated in Figure 1, and the specific logic for each hypothesis is provided below.

\section{Trustworthiness of top management}

We suggest that perceptions of the trustworthiness of top management minimize the threat inherent in downsizing by helping survivors to understand and believe in management's intentions and expected behavior. Trustworthiness is defined as an individual belief that top management can be trusted, where

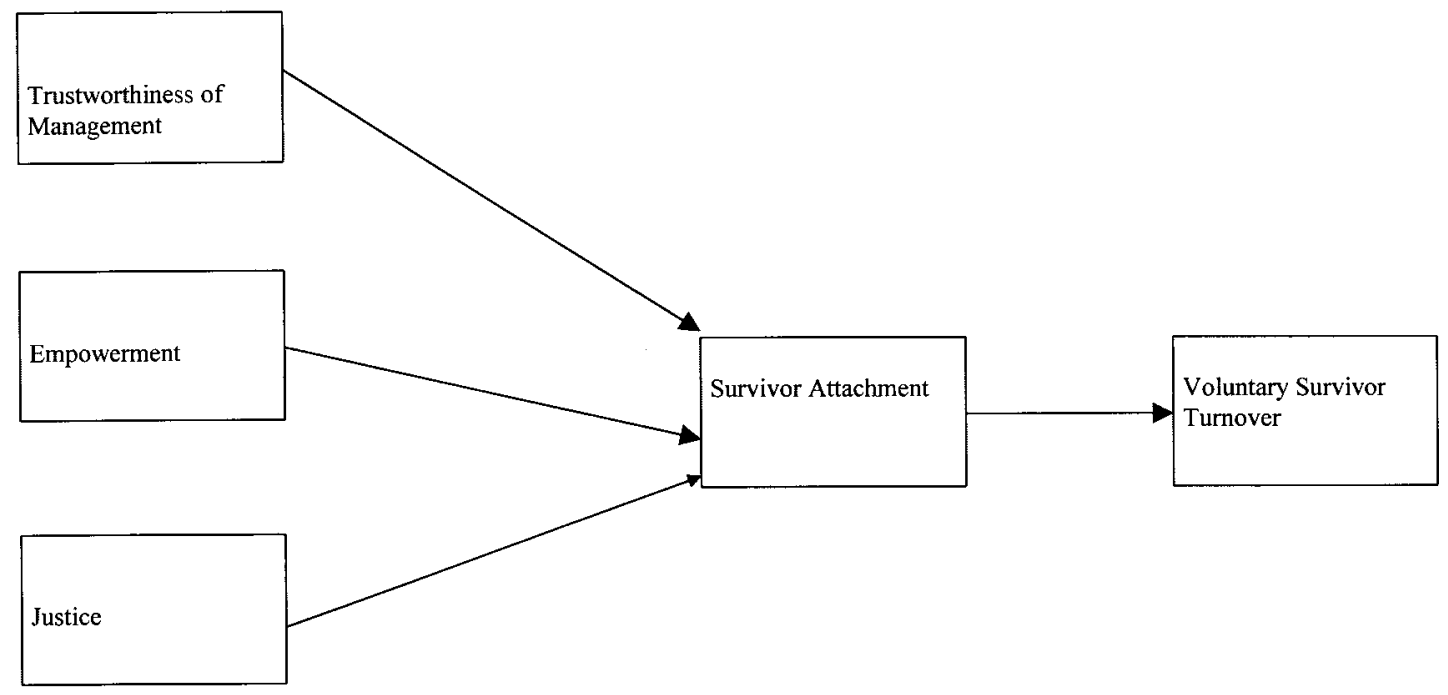

Figure 1. Theoretical framework 
trust is a defined as a willingness to be vulnerable to others (Granovetter, 1985; Lewis \& Weigert, 1985; Mayer, Davis, \& Schoorman, 1995; Sitkin \& Roth, 1993). Being vulnerable means that a significant potential for loss exists (Deutsch, 1973; Luhmann, 1979; Zand, 1972). Without this sense of trustworthiness, survivors may become cynical and withdraw, feeling less attached and fearful for their own job (Niehoff et al., 2001). Trust allows closer attachments because it minimizes the threat of malfeasance (Fukuyama, 1995; Golembiewski \& McConkie, 1975). Trust in management enhances the perceived legitimacy of organizational changes (Rousseau \& Tijoriwala, 1999). Trust in the leader has also been found to mediate the relationship between leader behavior and commitment (Pillai, Schriesheim, \& Williams, 1999).

Several key dimensions of trustworthiness have been documented in the management literature, including a concern for others' interests, competence, openness or honesty, and reliability (Hart \& Saunders, 1997; Mayer et al., 1995; Mishra, 1996). A belief that management is concerned about the best interests of survivors leads them to feel more attached because survivors believe that top management is acting in the interests of survivors as well as themselves so there is a benefit to staying connected. Survivors who believe that management is competent may also feel more attached because they view top management as capable of enhancing the organization's competitive position, thereby increasing survivors' sense of a future with the organization. Survivors who believe that top management is reliable may also feel more attached because they believe that top managers will follow through with what is expected. Finally, survivors who believe that top management is being open and honest about what is happening (O’Neill \& Lenn, 1995) may feel more attached because they believe promises will be kept in the future.

Therefore, a belief in the trustworthiness of top management can help to reduce the threat inherent in downsizing and help survivors to feel more attached to the organization. In fact, Brocker, Siegel, Daly, Tyler, and Martin (1997) did indeed find trust to be significantly related to organizational commitment, particularly when outcomes were relatively unfavorable. Thus, we hypothesize the following.

Hypothesis 1: Survivors who perceive top management as more trustworthy will feel more attached to the organization than those who perceive top management as less trustworthy.

\section{Justice}

The perceived justness of the downsizing implementation will reduce the degree to which the downsizing is evaluated as threatening by reducing the ambiguity of the expected outcome from the encounter (cf. Folkman, 1984). Prior research has demonstrated a relationship between justice perceptions and attitudinal commitment (Cohen-Charash \& Spector, 2001) but ultimately to intentions to quit (Konovsky \& Cropanzano, 1991) and turnover (Aquino, Griffeth, Allen, \& Hom, 1997). When individuals feel they have been treated unfairly, it reduces their satisfaction, which increases cognitions about withdrawal (Aquino et al., 1997). Specific to a downsizing context, Brockner and his colleagues have produced a significant body of research showing that perceptions of justice have a strong influence on survivors' attachment to the organization, following a downsizing (e.g., Brockner, DeWitt, Grover \& Reed, 1990; Brockner, Grover, Reed, \& DeWitt, 1992a; Brockner, Wiesenfeld, \& Martin, 1995; Brockner, Wiesenfeld, Reed, Grover, \& Martin, 1993). We discuss three kinds of justice: distributive, procedural, and interactional.

\section{Distributive justice}

Distributive justice reflects the fairness of the outcomes resulting from the downsizing (Brockner \& Greenberg, 1990). Drawing on Thibaut and Walker (1975), distributive justice matters for attachment because people are concerned with receiving desired outcomes. As desired outcomes become less 
available, attachment will thus decrease precipitously. Because distributive justice facilitates less threatening appraisals about the availability of desired outcomes, we suggest that increasing levels of distributive justice will lead to more survivor attachment to the organization. When survivors feel more threatened, their attachment to the organization becomes weaker as the individual's identification with the organization suffers. In a meta-analysis (Cohen-Charash \& Spector, 2001), distributive justice has been found to be significantly and positively related to affective commitment $(r=0.37)$ and negatively related to turnover intentions $(r=-0.26)$.

Distributive justice often is operationalized as how the victims of the downsizing have been treated because survivors view victims as valued friends or colleagues. Thus, if survivors believe that the victims of the downsizing received fair outcomes, they will be less likely to consider top management as adversarial but rather perceive them as helpful in easing the transition for victims, and thus will feel more attachment to the organization. Survivors are also likely to feel more attached because they anticipate they will receive similar generous benefits should they lose their own jobs in the future.

Another element of distributive justice is the extent to which the burden of the downsizing is shared across levels of the organizational hierarchy. For example, in one organization, executives received significant performance bonuses at the same time that lower level employees were laid off with minimal severance packages (Dial \& Murphy, 1995). We suggest that resource allocations that favor top management at the expense of survivors or victims will result in more threatening appraisals and less attachment; in such cases, survivors are likely to believe that the allocation of scarce resources has been unfair and that they will suffer disproportionately, hurting their attachment to the organization and particularly to its management (Brockner \& Greenberg, 1990). Sharing the burden across levels creates the perception that everyone is 'in this together,' thus reducing threat and increasing attachment. Thus, we hypothesize that:

Hypothesis 2: Survivors who appraise the downsizing as more distributively just will feel more attached to the organization than those who appraise it as less distributively just.

\section{Procedural justice}

Procedural justice reflects the fairness of the processes used to implement the downsizing (Brockner \& Greenberg, 1990). As opposed to the instrumental viewpoint described above which emphasizes material benefits, the group-value theory, which underlies notions of procedural justice (Lind \& Tyler, 1988), assumes that people value their relationships with social entities. As a result, it matters to people whether they are accepted, respected, and valued in interactions with others. Fair treatment is a reflection of being respected and valued, thereby bolstering their sense of attachment to the social system (Brockner, Tyler, \& Cooper-Schneider, 1992b). In contrast, that attachment is severely impacted when people feel like they are being treated unfairly. In a meta-analysis (Cohen-Charash \& Spector, 2001), procedural commitment has been found to be significantly and positively related to affective commitment $(r=0.43)$ as well as negatively related to turnover intentions $(r=-0.26)$.

Procedural justice has typically been operationalized in terms of the decision rule to determine who is laid off and in terms of advance notice provided about the timing of the downsizing (Brockner et al., 1992b; Brocker et al., 1994). When the decision rule to determine whom to lay off is based on a clearly defined decision rule rather than favoritism or politics, a survivor is more likely to appraise the downsizing as more predictable and will feel less threatened. In contrast, when survivors perceive the decision rule to be politically based or biased, they are less likely to see the implementation as fair and thus feel less attached (Tyler \& Bies, 1990).

Advance notice (Brockner et al., 1994; Kozlowski, Chao, Smith, \& Hedlund, 1993) enables individuals to feel attached because the probability of an unannounced downsizing in the future, which may affect them, has been minimized. Rather than feeling incapacitated by anxiety about a future downsizing, if they 
have the assurances of advance notice, survivors can lower their defenses because they know they will be given adequate time to prepare for a downsizing in the future, if necessary. Thus, advance notice will help reduce survivor perceptions of threat and create more attachment to the organization.

Hypothesis 3: Survivors who appraise the downsizing as more procedurally just will feel more attached to the organization than those who appraise it as less procedurally just.

\section{Interactional justice}

Interactional justice is an extension of procedural justice and is focused on the interpersonal side of organizational practices, specifically the interpersonal treatment and communication by management to employees, often in terms of dignity, respect, and politeness. It typically focuses on at least three types of social accounts, or verbal strategies, used to minimize the apparent severity of an encounter (Bies, 1987; Brockner \& Greenberg, 1990; Tyler \& Bies, 1990): (a) causal accounts that focus on credible mitigating circumstances for the downsizing (e.g., 'We had to lay off workers because of an economic recession that was beyond our control'); (b) ideological accounts that link the downsizing to a vision of the organization's future (e.g., 'Laying off workers will help improve our company's competitive advantage in the future'), and (c) penitential accounts that focus on the interpersonal treatment of those who are affected by the downsizing (e.g., 'We are really sorry to have had to resort to layoffs'). Research has shown that offering explanations of why the unpopular events must happen ameliorates negative reactions and promotes the belief that decision makers' actions were fair and the result of good judgment (Bies, 1987).

Regarding the first type of account, survivors will feel more attached to the organization when the rationale for the downsizing addresses the mitigating circumstances in the external environment, rather than the enrichment of shareholders or top management (Brockner \& Greenberg, 1990). Regarding the second type of social account, communicating a clear vision of how the downsizing will benefit all stakeholders increases attachment because survivors can see a real future for the organization. This type of social account reframes the event by placing the downsizing in a broader context that will legitimate action. And regarding the third type of social account, when survivors are treated humanely and with dignity, they will feel more attached because they feel valued and appreciated, rather than feel blamed.

Each of these social accounts reduces the threat inherent in the downsizing and can contribute to greater feelings of attachment in survivors because survivors can understand the logic underlying the downsizing. In a meta-analysis (Cohen-Charash \& Spector, 2001), interactional justice has been found to be significantly and positively related to affective commitment $(r=0.42)$ and negatively related to turnover intentions $(r=-0.32)$.

This logic is also consistent with work on psychological contracts. Relational elements of the psychological contract include the expectation that the organization will treat employees with dignity and respect in return for their attachment to the organization (Rousseau, 1995). When these types of social accounts aren't used as part of the downsizing, employees feel the organization is violating the psychological contract, resulting in lower levels of attachment.

Hypothesis 4: Survivors who appraise the downsizing as more interactionally just will feel more attached to the organization than those who appraise it as less interactionally just.

\section{Empowerment}

As described at the beginning of the paper, compared to trust and justice, there has been much less focus on the role of empowerment in downsizing. But downsizing contexts can in fact provide opportunities for empowerment. Employees may feel more self-determination as a result of fewer 
layers of management remaining after a downsizing. And their jobs will be more enriched as they take on new activities and work with new colleagues (Brockner et al., 1993). When provided opportunities for more control over their work environment, survivors' fears and insecurities are lessened (Cameron, Freeman, \& Mishra, 1993; Greenhalgh \& Rosenblatt, 1984). Because of their strong sense of personal control, empowered survivors may feel more hardy (cf. Wiebe, 1991) and engage in more proactive coping to reduce the potential for strain (cf. Aspinwall \& Taylor, 1997). Feeling empowered may be a starting point for mending problems and building commitment (Niehoff et al., 2001) because it leads to greater personal initiative (cf. Frese, Fay, Hilburger, Leng, \& Tag, 1997). And with an enhanced sense of personal control, empowered individuals are able to actively cope with challenges, protecting them from strain, and even leading to learning and health (Wall, Jackson, Mullarkey, \& Parker, 1996; Parker \& Spriggs, 1999). The feelings of personal control underlying empowerment enable people to deal with job difficulties more actively (Frese \& Fay, 2001).

We define empowerment as a personal sense of control in the workplace as manifested in four beliefs about the person-work relationship: meaning, competence, self-determination, and impact (Spreitzer, 1995; Thomas \& Velthouse, 1990). Meaning reflects a sense of purpose or personal connection about work. A strong sense of meaning helps individuals to cope with the uncertainly because it provides purpose amidst the upheaval. Competence indicates that individuals believe they have the skills and abilities necessary to perform their work well. Competence thus helps survivors feel that they have the personal resources to cope with the change in their work context. Self-determination reflects a sense of freedom about how individuals do their own work. This self-determination helps survivors to feel more in control over how they cope with the downsizing. And impact describes a belief that individuals can influence the system in which they are embedded. This impact enables survivors to feel they can make a difference through their actions.

Thus, each dimension enables survivors to better cope with the downsizing and thus preserves their attachment to the organization, even among the difficult times. 'People fear and tend to avoid... situations they believe exceed their skills whereas they get involved in activities and behave assuredly when they judge themselves capable of handling situations that would otherwise be intimidating' (Lazarus \& Folkman, 1984). Without having a sense of control over a stressful situation, individuals will withdraw into a state of helplessness (Greenberger \& Strasser, 1986) rather than enabling attachment. When empowered, however, employees do not feel as though they are mere 'cogs' in a machine but more as owners of the organization (Bell \& Staw, 1989). Thus, empowered survivors are more likely to respond actively, believing they can shape and influence the downsizing situation for the better, giving them a reason to want to stay connected to the organization. Thus, we argue that the four dimensions of empowerment should help survivors feel more in control, should help them to cope with the demands of the downsizing, and hence should increase their attachment to the organization.

Related empirical research is consistent with a relationship between empowerment and organizational attachment. As an example, though conducted in non-downsizing contexts, empowerment has been found to be positively related to loyalty (Fulford \& Enz, 1995), positively related to affective commitment (particularly the self-determination and impact dimensions) (Kraimer, Siebert, \& Liden, 1999; Wu \& Short, 1996), and negatively related to a propensity to turnover (Koberg, Boss, Senjem, \& Goodman, 1999). Moreover, research has found that personal control (which captures the selfdetermination and impact dimensions of empowerment) is positively related to affective commitment (Spector, 1986). And, following a downsizing, empowered survivors have been found to remain more loyal to the organization due to having more enriched jobs (Niehoff et al., 2001).

Hypothesis 5: Survivors who feel more empowered (in terms of meaning, competence, selfdetermination, and impact) during the downsizing will feel more attached than those who feel less empowered. 


\section{Attachment and voluntary turnover}

The relationship between attachment to the organization and voluntary turnover has been well documented (Cohen, 1993; Cohen \& Hudecek, 1993). Employees with strong attachments wish to remain with their employing organizations (Mowday, Steers, \& Porter, 1982). Strong organizational attachment engenders a positive attitude toward the organization and increase intentions to stay. When individuals feel more connected and attached to the organization, they want to be part of the future of the organization and thus will be less likely to voluntarily turn over following the downsizing. In fact, a meta-analysis (Mathieu \& Zajac, 1990) has shown a consistent but negative relationship between one particular type of attachment, organizational commitment, and voluntary turnover $(r=-0.33)$. However, none of these studies were conducted in a downsizing context. Thus, it is important to confirm this relationship in a downsizing context.

Hypothesis 6: Survivors who feel more attached to the organization will be less likely to voluntarily turnover than survivors who feel less attached.

\section{Mediating effect of attachment}

As shown in Figure 1, our theoretical framework indicates a mediating effect of attachment on the relationship between the trust, justice and empowerment predictors and subsequent job turnover. We suggest that the effects that trust, justice, and empowerment may have on actual withdrawal behavior will be captured by the attachment facilitated by these constructs. Individuals make sense of the downsizing context by creating an overall impression of their connection or attachment to the organization - and it is the overall impression of their attachment that ultimately influences their withdrawal behavior in terms of actual turnover. Consequently, we suggest that attachment will capture the essence of the relationship between trust, justice, and empowerment on turnover.

Hypothesis 7: Survivor attachment to the organization will mediate the relationship between trust, justice, and empowerment and voluntarily turnover.

\section{Organizational Context}

The data for this article were drawn from a larger research project investigating the roles that employee empowerment and trust in management have in shaping individuals' responses to organizational downsizing. Gretchen Spreitzer and Aneil Mishra conducted this study while they were on the faculty at the University of Southern California and the Pennsylvania State University, respectively. It is an example of their ongoing collaborative research begun more than a decade ago while the two were doctoral students together at the University of Michigan.

The business unit that provided the sample of employees for our paper was one of two units studied as part of a larger study examining employee responses to organizational change during adversity. These two business units belonged to the aerospace division of an established, profitable, Fortune 100 conglomerate operating during a period of significant consolidation and employee layoffs in the aerospace industry. This consolidation and downsizing was taking place even as the U.S. 
continued its economic expansion begun several years earlier. The aerospace division itself was comprised of more than a dozen business units located throughout the U.S., and our two units were located in the Southwestern U.S. Top management of the aerospace division planned at some point during our study to target each of the business units for downsizing, outright closure, or transfer of employees from other downsized or closed units. Survey data were collected from both sites in the summer of 1996, and turnover data were collected from company archives for the year subsequent to the survey data collection.

Our sample consisted of individuals employed in either hourly or salaried positions that typically required either a four-year college degree or extensive technical education. These employees included design and process engineers; sales, marketing, and administrative support personnel; machinists, assemblers and inspectors, as well as supervisors and department managers. As is typical in the aerospace industry, most of the salaried employees had dual reporting arrangements, reporting to both functional heads as well as project managers responsible for the design, manufacture, and sales of commercial aircraft components.

In order to gain the trust necessary to be able to survey employees during this turbulent time, the two authors agreed to serve on a three month-long task force two years before our survey data were collected. The task force was charged with identifying best management practices in organizational downsizing. As part of this effort, we (along with another researcher) interviewed a score of individuals within the conglomerate and with executives and employees in other companies that were currently undergoing downsizings. We and the other researcher then wrote a technical report that was provided to the aerospace division's top management. We also provided confidential feedback reports to top management within two months following the completion of the survey research phase of the study. Several follow-up meetings and visits were necessary in order to collect the employee turnover data that are part of this study.

\section{Methods}

\section{Sample and data collection procedures}

Surveys were administered to a sample of 731 full-time aerospace employees at a unionized plant undergoing a downsizing. The downsizing announcement that 10 per cent of the site's contract workers were to be laid off was made approximately one month before the surveys were distributed. These contract workers had worked at the firm for many years, often as part of teams composed of regular employees. Their work content was indistinguishable from that of regular employees. Discussions with employees at the downsizing plant indicated that the non-contract employees who completed the survey experienced this as a very real downsizing and felt that they typified 'survivors' due to the loss of their long-time coworkers. Everyone in the organization was potentially susceptible to being laid off as part of the formal downsizing announcement - the laid-off contract employees were simply the initial victims of the downsizing effort.

A total of 350 employees responded for a response rate of 48 per cent. Due to missing data, the number of usable surveys available for analyses was 331. Respondents were assured of the confidentiality of their responses. All surveys were mailed back directly to the researchers. The employees who responded were 70 per cent male with an average age of 43 years, 10 years of service at the company, and some college education. Using a $t$-test of independent samples, we found that non-respondents did 
not look significantly different on sex (69 per cent of non-respondents were male which was not significantly different from respondents, $p<0.96$ ) and years of company service (average tenure of 10 years which also was not significantly different from respondents, $p<0.63$ ). Non-respondents, however, were significantly younger (average age of 41 years which was significantly different than respondents, $p<0.003$ ). Because level of education was only measured as part of the survey, differences with non-respondents could not be computed.

One year later, turnover data were collected from archival sources. During that time period, no significant organizational changes, such as new leadership, new technology systems, or new benefits systems, occurred. As an additional check on response bias, we also examined whether there were significant differences on eventual turnover from the company based on response to the survey. In a $t$-test, we found no significant differences in turnover rate across responders/non-responders $(p<0.223)$.

\section{Measures}

All survey measures were assessed with 7-point Likert scales ranging from very strongly disagree to very strongly agree. To the extent possible, we used already validated scales for each variable in the model.

\section{Trust}

We used Mishra and Mishra's (1994) 16-item measure of trustworthiness. A sample item for each of the four dimensions include: 'I believe that site management tells the truth' (openness); ' ... provides capable and competent leadership' (competence); '... does not try to get out of its commitments' (reliable), and '... would make personal sacrifices for our organization' (concern). To reduce the size of the instrument, we used the three items per dimension which Mishra and Mishra have found to be highest loading in their research. Previous research has shown that the four dimensions can be aggregated into a single trustworthiness scale (Mishra \& Mishra, 1994). Based on the results of the confirmatory factor analysis discussed below and because the dimensions were correlated at about 0.80 , we aggregated the trustworthiness items and their respective dimensions for testing our hypotheses. We found the aggregated trustworthiness scale to have an acceptable level of reliability $(\alpha=0.96)$.

\section{Justice}

Our measures of distributive and procedural justice were adapted from Niehoff and Moorman (1993) by changing the wording to fit a downsizing context. We also created our own measure of interactional justice, as no appropriate measure was available at the time the data were collected. The items measuring these three dimensions of justice are included in the appendix, and all achieved acceptable levels of reliability (distributive justice, $\alpha=0.90$; procedural justice, $\alpha=0.91$; interactional justice, $\alpha=0.86$ ).

\section{Empowerment}

We used Spreitzer's (1995) 12-item measure of empowerment. Sample items for each of the four dimensions include: 'The work I do is very important to me' (meaning); 'I am confident about my ability to do my job' (competence); 'My impact on what happens in my department is large' (impact); 'I have significant autonomy in determining how I do my job' (self-determination). Previous research has shown that the four dimensions can be aggregated into a single scale (Kraimer et al., 1999) or used individually (Spreitzer, Kizilos, \& Nason, 1997). Because the dimensions are not very highly correlated, we retain the individual dimensions so we can more clearly observe the separate effects of the different dimensions. Each dimension has an acceptable level of reliability (meaning, $\alpha=0.91$; competence, $0.80 ; \alpha=$ self-determination, $\alpha=0.76$; impact, $\alpha=0.81$ ). 


\section{Attachment}

In this paper, we focus on one specific element of organizational attachment - affective commitment, or the relative strength of an individual's identification with the organization (Mowday, Steers, \& Porter, 1982). We focus on affective commitment because we believe that it will be the component of commitment most influenced by the variables in our model - trust, justice, and empowerment. Continuous commitment would be more influenced by investments like pension benefits that would be lost upon leaving. Moreover, almost all commitment research on turnover has focused on affective commitment (Tett \& Meyer, 1993).

To measure affective commitment, we drew three items from Mayer and Schoorman's $(1992 ; 1998)$ 9-item measure of value commitment which is drawn from Mowday, Steers, and Porter's (1979) OCQ: 'I talk up my company as a great organization to work for'; 'I am willing to put in effort beyond what is normally expected'; 'My company really inspires the very best in me in the way of job performance'. Because our 3-item measure was not previously validated, we assessed its convergent validity against the 9-item measure of value commitment. Using the dataset published by Mayer and Schoorman (1992; 1998) consisting of two waves of data from a financial services firm (288 respondents in the first wave, 220 in the second), we correlated our 3-item measure with the 9-item measure. The resulting correlations of 0.93 for each wave of data indicate that using the abbreviated measure loses little information. Our 3-item measure also achieved an acceptable reliability of 0.72 .

We conducted a confirmatory factor analysis (using LISREL 8.30) of the survey measures of the constructs in our theoretical framework. After trimming two individual trustworthiness items that cross-loaded on two justice factors, we found that the overall fit indices provide moderate evidence for our hypothesized model $\left(\chi_{629}^{2}=1345.96(p=0.0), \mathrm{RMSR}=0.05, \mathrm{NNFI}=0.90, \mathrm{CFI}=0.91\right.$, $\mathrm{IFI}=0.91$, RMSEA $=0.062$ ). All individual item factor loadings were significant, ranging from 0.39 to 0.94 . Correlations among the latent variables were significant and ranged from -0.23 to 0.75 (between trustworthiness and distributive justice).

\section{Turnover}

Turnover was measured from company records one year following the downsizing announcement. This time lag is approximately halfway between the two time lags observed by Allen et al. (2001). Whether an employee voluntarily left the organization was compiled from employee records obtained from the human resources department, not by supervisor recollections. Our turnover variable was given a score of zero if the employee was still with the firm one year after the survey data were collected and a score of one if they had voluntarily left the firm by that time. In our dataset, 13 employees had voluntarily left the organization over one year. Employees who were transferred to another business unit were excluded from the sample as were two individuals who were fired for cause (i.e., involuntary turnover).

\section{Control variables}

Several additional variables (education, age, organizational tenure) were included as controls in the analyses because they may also have effects on survivor attachment and turnover. Educational level was measured as a seven-category scale ranging from less than high school to doctoral degree. Survivors with higher levels of education may have greater skills and capacity to cope with the stress associated with the downsizing and thus may have more attachment. A meta-analysis found education to be negatively related to affective commitment (Mathieu \& Zajac, 1990) and positively related to voluntary turnover (Griffeth, Hom, \& Gaertner, 2000). The age of the employee (measured as number of years) was collected from archival sources. Younger employees have been found to be more likely to initiate turnover in a meta-analysis (Griffeth et al., 2000). Older workers may believe they have fewer up-to-date skills and are more likely to be laid off in the future and may thus have less attachment. A meta-analysis found age to be positively related to affective commitment (Mathieu \& Zajac, 1990). 
Length of service or company tenure (measured as years of employment at the organization) and sex were also collected from archival sources. Those survivors with longer tenures at the organization may have greater psychological attachment to the firm or more firm-specific skills due to their longevity and thus may be less likely to leave the organization. Once again, a meta-analysis has consistently found organizational tenure to be positively related to affective commitment (Mathieu \& Zajac, 1990) and negatively related to voluntary turnover (Griffeth et al., 2000). Sex was also included, as some research suggests that female downsizing survivors do differ from male survivors in how much they perceive threat of job loss following a downsizing (Armstrong-Strassen, 1998). In general research on voluntary turnover, however, no difference has been found in quit rates of men and women (Griffeth et al., 2000). However, women have been found to be slightly more committed than men (Mathieu \& Zajac, 1990).

Three additional variables from the unfolding model of turnover (Mitchell \& Lee, 2001), which reflect community linkages, are also included as control variables. We asked respondents if they are the primary source of income for their family (yes/no), the number of school age children at home, and if they had elderly dependents (yes/no). Kinship responsibilities and number of children and elderly dependents have been found to improve retention (Lee \& Mauer, 1999).

\section{Results}

Listwise deletion of missing data was used in all analyses. Table 1 contains the means, standard deviations, and correlations for the variables in the analyses. The correlations indicate initial support for the hypotheses. Supporting Hypotheses 1-6, trustworthiness in top management, the three justice dimensions and the four empowerment dimensions are significantly and positively related to organizational attachment. Supporting Hypothesis 7, survivor attachment is significantly and negatively related to turnover.

Table 2 includes the regression analyses used to examine the hypotheses. To test Hypotheses 1-5, we regressed attachment to the organization on the independent variables in the framework, controlling for all of the control variables. For this analysis, we used OLS regression (see column 2 of Table 2). All variables were entered simultaneously. The regression equation explained 51 per cent of the variance in commitment. Only one control variable, education, was significant. It suggests that more educated survivors tend to have lower levels of commitment than less educated survivors.

Support is found for Hypothesis 1 . The trustworthiness of management $\left(\beta=0.17^{\ddagger}\right)$ is found to be related to higher assessments of commitment. Support is found for Hypothesis 2. When survivors perceive the downsizing to be more distributively just $\left(\beta=0.15^{\ddagger}\right)$, they feel more committed. Support is also found for Hypothesis 3. When survivors perceive the downsizing to be handled in a manner that is more procedurally fair $\left(\beta=0.12^{\dagger}\right)$, they report higher levels of commitment. Support is not found for Hypothesis 4. Survivor assessments of interactional justice $(\beta=0.04$, n.s.) are not found to be related to their commitment. So support is found for two of the three justice constructs.

Support is also found for Hypothesis 5, which links the four dimensions of empowerment to commitment. The meaning dimension $\left(\beta=0.26^{\|}\right)$, the competence dimension $\left(\beta=0.10^{\dagger}\right)$, the selfdetermination dimension $\left(\beta=0.07^{*}\right)$, and the impact dimension $\left(\beta=0.24^{\|}\right)$are each found to be significantly related to commitment, though self-determination is only marginally significant. Thus, the results of this regression analyses provide support for the roles of trust, justice, and empowerment in preserving survivor empowerment following a downsizing.

To test Hypothesis 6, we conduct a logistic regression (the results are provided in columns 3-6 of Table 1). Because a binary dependent variable like turnover (i.e., staying or leaving) violates the 


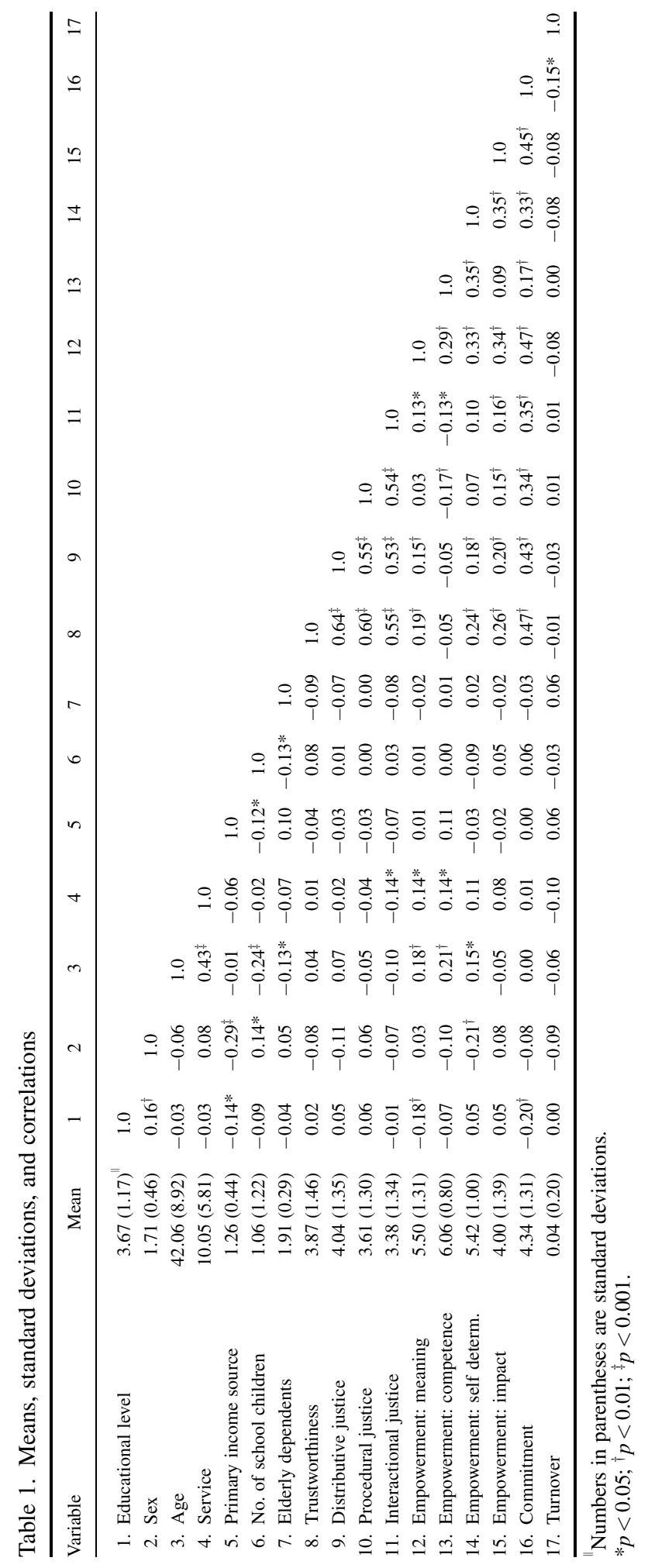


Table 2. Results of regression analyses

\begin{tabular}{|c|c|c|c|c|c|}
\hline Independent variable & $\begin{array}{l}\text { Commitment } \\
\text { (OLS) }\end{array}$ & $\begin{array}{c}\text { Turnover B } \\
\text { (Logistic) }\end{array}$ & $\begin{array}{l}\text { Turnover } \\
\text { S. E. }\end{array}$ & $\begin{array}{c}\text { Turnover } \\
\text { Wald Statistic }\end{array}$ & $\begin{array}{c}\text { Turnover } \\
\operatorname{Exp}(\mathrm{B})\end{array}$ \\
\hline \multicolumn{6}{|l|}{ Control variables } \\
\hline Education & $-0.18^{\|}$ & -0.24 & 0.37 & 0.44 & 0.79 \\
\hline Sex & -0.03 & -1.16 & 0.91 & 1.61 & 0.32 \\
\hline Age & -0.07 & -0.01 & 0.05 & 0.07 & 0.99 \\
\hline Years of Service & -0.03 & -0.12 & 0.10 & 1.45 & 0.89 \\
\hline Primary Income Source & -0.02 & -0.09 & 0.86 & 0.01 & 0.91 \\
\hline Number Children & 0.00 & -0.07 & 0.32 & 0.05 & 0.92 \\
\hline Elderly Dependents & -0.01 & 6.56 & 30.68 & 0.05 & 703.85 \\
\hline \multicolumn{6}{|l|}{ Predictor variables } \\
\hline Trustworthiness of Management & $0.17^{\ddagger}$ & 0.16 & 0.37 & 0.20 & 1.175 \\
\hline Distributive Justice & $0.15^{\ddagger}$ & 0.06 & 0.37 & 0.02 & 1.06 \\
\hline Procedural Justice & $0.12^{\dagger}$ & 0.38 & 0.43 & 0.77 & 1.46 \\
\hline Interactional Justice & 0.04 & 0.10 & 0.42 & 0.06 & 1.10 \\
\hline Empowerment: Meaning & $0.26^{\|}$ & 0.06 & 0.29 & 0.05 & 1.07 \\
\hline Empowerment: Competence & $0.10^{\dagger}$ & 0.23 & 0.46 & 0.25 & 1.26 \\
\hline Empowerment: Self-Determination & $0.07 *$ & -0.31 & 0.42 & 0.53 & 0.73 \\
\hline Empowerment: Impact & $0.24^{\|}$ & 0.11 & 0.30 & 0.14 & 1.12 \\
\hline Commitment & - & $-0.93^{\dagger}$ & 0.42 & 4.88 & 0.39 \\
\hline$R^{2}$ & 0.51 & & & & \\
\hline$F$ & $18.48^{\| \prime}$ & & & & \\
\hline-2 Log likelihood & & 70.09 & & & \\
\hline Model chi square & & 16.69 & & & \\
\hline Chi square $d f$ & & 16 & & & \\
\hline Cox Snell $R^{2}$ & & 0.06 & & & \\
\hline
\end{tabular}

${ }^{*} p<0.10 ;{ }^{\dagger} p<0.05 ;{ }^{\ddagger} p<0.01 ; " p<0.001$ - One tailed tests.

Beta coefficients are presented.

assumptions of ordinary least squares regression, we conducted log linear regression analysis rather than the more typical ordinary least squares regression. The error terms from prediction cannot be normally distributed nor homoscedastic (Lee \& Mowday, 1987). Consequently, all estimates using OLS regression are statistically inefficient. In contrast, log linear models better meet the underlying assumptions and allow for meaningful probability statements and statistically efficient estimates (Cox, 1970).

When log linear (logistic regression) analysis was conducted, support for Hypothesis 6, that more committed survivors would have a lower likelihood of voluntary turnover, was found. When both the predictor and control variables were entered, the $-2 \log$ likelihood function was 70.09 , with a chisquared improvement of fit (over the constant) equal to 16.69. None of the predictors of commitment was related to voluntary turnover. One control variable, education, was negatively related to turnover. Commitment was found to be significantly related to turnover $(\beta=-.093 \mathrm{~T})$. This logistic regression indicates that 96.9 per cent of the cases were correctly classified as having turned over or having remained with the firm.

We used path analysis to assess Hypothesis 7, the mediating hypothesis. To ascertain the extent of mediation, we tested the relationships between (1) trust, justice, and empowerment and turnover, (2) organizational commitment and turnover and (3) trust, justice, and empowerment and organizational commitment (Baron \& Kenny, 1986). While no direct effects between trust, justice, and empowerment and turnover were explicitly hypothesized, these effects must be estimated in the assessment of the mediating effect. If any direct effects are reduced or eliminated with the addition of the commitment mediator, then partial or full mediation is supported. 
From the above analyses, we know that conditions (2) and (3) hold. However, we do not find support for the direct effects of trust, justice, and empowerment on turnover. In a separate logistic regression, none of the dimensions of trust, justice, and empowerment were significantly related to turnover. So because this first condition fails to hold, we can conclude that there is no mediation effect and thus Hypothesis 7 is not supported. Instead, we know that trust, justice, and empowerment are each related to organizational commitment and that in turn organizational commitment is related to turnover.

\section{Discussion}

This research is the first to examine some of the long-term consequences of downsizing for the retention of survivors. Prior research has looked at more immediate reactions in terms of survivor loyalty (Niehoff et al., 2001) and commitment (Brockner et al., 1987, 1992b, 1993). As such, we have had little understanding of how downsizing can affect the long-term attachment of surviving employees to the firm. This attachment is believed to be critical for the kind of employee involvement necessary for the organization to turn its performance around following a downsizing (Mishra et al., 1998). Thus, a contribution of this research to the literature on survivor responses is a first look at the long-term behavioral consequences of downsizing.

This research also provides a partial empirical test of the Mishra and Spreitzer (1998) model of survivor responses to downsizing, extending the model to look beyond attitudinal outcomes to look at turnover behaviors. The research suggests that when survivors feel more attached to the organization, they are more likely to remain with the organization in the year subsequent to the downsizing. The research also provides some additional insight into what can influence more survivor attachment. Prior research has already indicated support for the roles of trust and justice. But we knew little role about empowerment in understanding survivor responses to downsizing. Support is also found for the importance of empowerment in helping survivors to feel attached to the organization following the downsizing. In fact, the meaning and impact dimensions of empowerment have the strongest regression coefficients of any of the variables in the model. Empowerment increases employees' belief that they can cope with the downsizing and that they have retain a semblance of personal control as the downsizing is implemented. Thus, this research also contributes to the literature on survivor responses to downsizing by examining the important role of empowerment.

The one hypothesis that was not supported was the finding regarding interactional justice. Interactional justice focused on the interpersonal relations between managers and employees, particularly in terms of social accounts providing for the rationale underlying the downsizing. The correlational analysis does suggest some multicollinearity among the justice dimensions as well as with trust. To explore whether multicollinearity may be contributing to the lack of significance of interactional justice, we conducted additional regression analyses for commitment where we dropped either distributive or procedural justice or dropped trustworthiness. However, in none of the regressions did interactional justice become significant. So if not multicollinearity, why the lack of significance?

It may be that survivors don't care so much about the rationale behind the downsizing. Other factors may be more important. The 'trustworthiness of top management' variable may be more important than having some rationale being provided. Furthermore, how victims are being treated, whether the burden is being fairly shared across the organization, whether advance notice is provided, and whether the decision rule for determining who will be laid off may be the more important factors in preserving survivor attachment. In fact, some justice researchers believe that interactional justice 
is just one component of procedural justice. Thus, procedural justice may be capturing what is important about interactional justice.

\section{Limitations and directions for future research}

One theoretical limitation of our work is that our framework does not include some economic or labor market determinants of the turnover decision. Obviously, variables such as what kind of job opportunities are available in the labor market for employees will have an important influence on whether individuals actually leave the organization when they are unsatisfied with the current situation. However, our intention was not to test a complete model of employee turnover (others have done this), but rather to look at the effects of survivor responses to downsizing on retention in the years following the downsizing.

One empirical limitation of this research is the potential for common method bias regarding the predictor variables and survivor attachment. While it would be preferable to have different referents provide different pieces of data to minimize the potential for common method bias, it is not clear conceptually who the appropriate referents would be for these variables beyond the survivor him or herself. Clearly, trustworthiness, justice, and empowerment as well as survivor attachment are all perceptual variables that must be self-assessed. So it is not clear how to avoid the problem of common method bias when the variables are examined from the most appropriate referent. The findings also indicate that common method bias is not the primary driver of the results given that not all variables using common methods are significant in the analyses.

A second limitation is the small amount of variance in voluntary turnover (we are explaining approximately 6 per cent of the variance in turnover). The imbalanced cell sizes between leavers and stayers may affect the results of the logistic regression. However, this amount of variance is comparable to that found in other turnover studies (see Griffeth, Hom, \& Gaertners' 2000 meta-analyses). In addition, one should not get too excited about explained variance in turnover research, as there is no good analog between the explained variance in the OLS $R^{2}$ sense and in logistic regression. At best, $R^{2}$ is a very loose and marginal-quality estimate with a binary dependent variable. In logistic regression, the regression weight itself and accuracy in prediction are the best empirical indicators of effect size.

There are many reasons beyond a person's control that influence their likelihood of leaving a firm. These include things like the favorability of the external job market, need for certain benefits which may be lost in changing employers, family constraints which may require an individual to stay in a limited geographic area due to children's schooling or care of elderly parent. While the amount of variance explained is small, it still is substantively important. If the cost of replacing lost employees and retraining their replacements is high, then reducing even a small amount of turnover is important for the organization.

A third limitation is the research design utilizing a single organization. We might have enhanced the variation in our predictor variables such as justice if we had looked across organizations where many different downsizing practices were institutionalized. But given that justice and the other predictors are conceptualized as psychological variables where employees can experience the same practices quite differently, we certainly are able to capture these differences in interpretation within this organization.

A strength of the research is that the ultimate dependent variable - actual voluntary turnover-is not subject to common method bias as it was collected from archival sources. The longitudinal nature of the data set (turnover data were collected one year following the initial data collection) is a further strength of the data set. Prior research on survivor responses has tended to look at more immediate reactions to downsizing such as job satisfaction or commitment. Thus, this research also contributes conceptually to the literature on survivor responses to downsizing in developing the logic for turnover as an outcome of interest. 
A further strength of the work is that we examine how the context of downsizing affects survivor responses and ultimately survivor turnover. The only other study, which has looked at turnover in a downsizing context, found demographic differences in turnover rates, but did not examine any contextual effects. Our research addressed this void by examining several important contextual effects of downsizing.

A direction for future research may be the use of survival analysis to examine not only whether survivors voluntarily turn over but also when they leave the organization. Somers and Birnbaum (1999) have shown that survival analysis has received only limited attention in turnover research and that it can provide some important new insights into understanding the temporal dynamics of voluntary turnover in downsizing. Using survival analysis, future research might examine whether some variables are more important for short-term retention while others might be important in the longer term. For example, trustworthiness might be most important for early leavers while empowerment may be more important for later leavers.

\section{Implications for practice}

Our theoretical framework suggests a number of strategies for managers to implement during a downsizing that may evoke more survivor attachment. First, facilitating perceptions of fairness is critical for influencing the hoped for, but often elusive, outcomes of downsizing. Researchers have shown that if the downsizing is not implemented fairly, employees who are more committed will actually respond to the downsizing in more dysfunctional ways than employees who are less committed (Brockner et al., 1992b). Thus, organizations may antagonize the employees who have the most to offer during a downsizing.

Second, the framework emphasizes the importance of empowering survivors in terms of meaning, competence, self-determination, and impact during a downsizing. Empowerment provides a buffer against the threat inherent in a downsizing initiative by helping survivors feel better able to cope. However, empowerment is often eroded during downsizing efforts as job security becomes more tenuous and survivors come to see themselves more as independent contractors than valued members of the firm. Empowerment may further erode as management takes on more control, which is typical during a crisis situation (D’Aunno \& Sutton, 1989; Staw, Sandelands, \& Dutton, 1981). The irony, then, is that downsizing may destroy the empowerment that is necessary to make or keep the organization competitive in the future.

Although the way in which the downsizing is implemented does make a difference, our framework highlights the importance of good long-term managerial relationships with employees, particularly in term of trust with management, beginning long before an announcement to downsize. In this way, effective downsizing is not a short-term fix, but rather a long-term investment in the human resources of the organization. This kind of investment in employees is particularly important after a downsizing, as a firm is likely to have less employee slack with which to absorb voluntary turnover. Moreover, those who were spared from the downsizing are likely to be quite valuable resources, indicating a greater need to retain them following the downsizing.

\section{Acknowledgements}

We thank William Cooke for his statistical help and Tom Lee and Joel Brockner for helpful comments on an earlier version of the manuscript. Roger Mayer was very generous in providing us use of his data 
to help validate our shortened measure of commitment. We especially appreciate Bob Schoeni's assistance with the statistical modelling. We also thank managers at the data sites, the University of Southern California's Marshall School of Business and Center for Effective Organizations, and Wake Forest University's Babcock Graduate School of Management's Research Fellowship Program for their support of this study.

\section{Author biographies}

Aneil K. Mishra is an Associate Professor of Management at the Babcock Graduate School of Management at Wake Forest University where he is also Faculty Director of the Full-Time MBA Program. His research focuses on trust within and between organizations, organizational culture, and leading change during adversity.

Gretchen M. Spreitzer is on the faculty at the University of Michigan Business School. She was previously on the faculty at the University of Southern California where much of the work for this paper was conducted. Her research focuses on employee empowerment and leadership development, particularly within a context of organizational change and decline.

\section{References}

Allen, T. D., Freeman, D. M., Russell, J. E. A., Reizenstein, R. C., \& Rentz, J. O. (2001). Survivor reactions to organizational downsizing: does time ease the pain? Journal of Occupational and Organizational Psychology, 74, 145-164.

Aquino, K., Griffeth, R. W., Allen, D. G., \& Hom, P. W. (1997). Integrating justice constructs into the turnover process: a test of a referent cognitions model. Academy of Management Journal, 40, 1208-1228.

Armstrong-Strassen, M. (1998). The effect of gender and organizational level on how survivors appraise and cope with downsizing. Journal of Applied Behavioral Science, 34, 125-141.

Aspinwall, L. G., \& Taylor, S. E. (1997). A stitch in time: self-regulation and proactive coping. Psychological Bulletin, 121, 417-436.

Baron, R. M., \& Kenny, D. A. (1986). The moderator-mediator distinction in social psychological research: conceptual, strategic, and statistical considerations. Journal of Personality and Social Psychology, 51, 1173-1182.

Bell, N. E., \& Staw, B. M. (1989). People as sculptors versus sculpture. In M. B. Arthur, D. T. Hall, \& B. S. Lawrence (Eds.), Handbook of career theory. New York: Cambridge University Press.

Bies, R. J. (1987). The predicament of injustice: the management of moral outrage. In B. M. Staw, \& L. L. Cummings (Eds.), Research in organizational behavior (Vol. 9, pp. 289-319). Greenwich, CT: JAI Press.

Bies, R., Martin, C., \& Brockner, J. (1993). Just laid off, but still a good citizen? Only if the process is fair. Employee Rights and Responsibilities Journal, 6, 227-238.

Brockner, J. (1990). Scope of justice in the workplace: how survivors react to coworker layoffs. Journal of Social Issues, 46, 95-106.

Brockner, J., \& Greenberg, J. (1990). The impact of layoffs on survivors: an organizational justice perspective. In J. S. Carroll (Ed.), Applied social psychology and organizational settings (pp. 45-75). Hillsdale, NJ: Erlbaum.

Brockner, J., \& Wiesenfeld, B. (1992). Living on the edge (of social and organizational psychology): the effects of job layoffs on those who remain. In J. K. Murnighan (Ed.), Social psychology in organizations: Advances in theory and research. Englewood Cliffs, NJ: Prentice-Hall.

Brockner, J., Davy, J., \& Carter, C. (1985). Layoffs, self-esteem, and survivor guilt: motivational, affective, and attitudinal consequences. Organizational Behavior and Human Decision Processes, 36, 229-244. 
Brockner, J., Dewitt, R., Grover, S., \& Reed. (1990). When it is especially important to explain why: Factors affecting the relationship between managers' explanations of a layoff and survivors' reactions to the layoff. Journal of Experimental Social Psychology, 26, 389-407.

Brockner, J., Grover, S. L., Reed, T. F., DeWitt, R. L., \& O’Malley, M. N. (1987). Survivors' reactions to layoffs: we get by with a little help for our friends. Administrative Science Quarterly, 32, 526-541.

Brockner, J., Grover, S. L., \& Blonder, M. D. (1988). Predictors of survivors' job involvement following layoffs: a field study. Journal of Applied Psychology, 73, 436-442.

Brockner, J., Grover, S. L., Reed, T. F., \& DeWitt, R. L. (1992). Layoffs, job insecurity, and survivors' work effort: evidence of an inverted-U relationship. Academy of Management Journal, 35, 413-425.

Brockner, J., Tyler, T. R., \& Cooper-Schneider, R. (1992). The influence of prior commitment to an institution on reactions to perceived fairness: the higher they are, the harder they fall. Administrative Science Quarterly, 37, 241-261.

Brockner, J., Wiesenfeld, B. M., Reed, T. F., Grover, S., \& Martin, C. (1993). Interactive effect of job content and context on the reactions of layoff survivors. Journal of Personality and Social Psychology, 64, 187-197.

Brockner, J., Wiesenfeld, B. M., \& Martin, C. L. (1995). Decision frame, procedural justice, and survivors' reactions to job layoffs. Organizational Behavior and Human Decision Processes, 63, 59-68.

Brockner, J., Konovsky, M., Cooper-Schneider, R., Folger, R., Martin, C., \& Bies, R. (1994). Interactive effects of procedural justice and outcome negativity and survivors of job loss. Academy of Management Journal, 37, 397-409.

Brockner, J., Siegel, P. A., Daly, J. P., Tyler, T., \& Martin, C. (1997). When trust matters: the moderating effects of outcome favorability. Administrative Science Quarterly, 42, 558-583.

Cameron, K. S., Freeman, S. J., \& Mishra, A. K. (1993). Organizational downsizing. In G. Huber \& W. Glick (Eds.), Organizational change and redesign: Ideas and insights for improving performance (pp. 19-65). New York: Oxford University Press.

Cascio, W. F. (1993). Downsizing: what do we know? What have we learned. Academy of Management Executive, 7, 95-104.

Cohen, A. (1993). Organizational commitment and turnover: a meta-analysis. Academy of Management Journal, 35, 1140-1157.

Cohen, A., \& Hudecek, N. (1993). Organizational commitment-turnover relationship across occupational groupsa meta analysis. Group and Organization Management, 13, 188-213.

Cohen-Charash, Y., \& Spector, P. (2001). The role of justice in organizations: a meta-analysis. Organizational Behavior and Human Decision Processes, 86, 278-321.

Cox, D. R. (1970). Analysis of binary data. New York: Chapman Hill.

D’Aunno, T., \& Sutton, R. I. (1989). The responses of drug abuse treatment centers to financial adversity: a partial test of the threat-rigidity thesis. Journal of Management, 18, 117-132.

Deutsch, M. (1973). The resolution of conflict: Constructive and destructive processes. New Haven, CT: Yale University Press.

Dial, J., \& Murphy, K. J. (1995). Incentives, downsizing, and value creation at General Dynamics. Journal of Financial Economics, 38, 261-314.

Folkman, S. (1984). Personal control and stress and coping processes: a theoretical analysis. Journal of Personality and Social Psychology, 46, 839-852.

Frese, M., \& Fay, D. (2001). Personal initiative: an active performance concept for work in the 21 st Century. Research in Organizational Behavior, 23, 133-187.

Frese, M., Fay, D., Hilburger, T., Leng, K., \& Tag, A. (1997). The concept of personal initiative: operationalizational, reliability and validity in two German samples. Journal of Occupational and Organizational Psychology, 70, 139-161.

Fukuyama, F. (1995). Trust: The social virtues and the creation of prosperity. New York: Free Press.

Fulford, M. D., \& Enz, C. A. (1995). The impact of empowerment on service employees. Journal of Managerial Issues, 7, 161-175.

Golembiewshik R. T., \& McConkie, M. (1975). The centrality of interpersonal trust in group processes. In C. L. Cooper (Ed.), Series on Group Professes (pp. 131-185). New York: Wiley.

Granovetter, M. (1985). Economic action and social structure: the problem of embeddedness. American Journal of Sociology, 91(3), 481-510.

Greenberger, D. B., \& Strasser, S. (1986). Development and application of a model of personal control in organizations. Academy of Management Review, 11, 164-177.

Greenhalgh, L., \& Rosenblatt, Z. (1984). Job insecurity: toward conceptual clarity. Academy of Management Review, 9, 438-448. 
Griffeth, R. W., Hom, P. W., \& Gaertner, S. (2000). A meta-analysis of antecedents and correlates of employee turnover: update, moderator tests, and research implications for the next millennium. Journal of Management, $26,463-488$.

Hart, P., \& Saunders, C. (1997). Power and trust: critical factors in the adoption and use of electronic data exchange. Organization Science, 8(1), 23-42.

Hom, P. W., Griffeth, R. W., \& Sellaro, C. L. (1984). The validity of Mobley's (1977) model of employee turnover. Organizational Behavior and Human Performance, 34, 141-174.

Hom, P. W., Caranikas-Walker, F., Prussia, G. E., \& Griffeth, R. W. (1992). A meta-analytical structural equations analysis of a model of employee turnover. Journal of Applied Psychology, 77, 890-909.

Iverson, R. D., \& Pullman, J. A. (2000). Determinants of voluntary turnover and layoffs in an environment of repeated downsizing following a merger: an event history analysis. Journal of Management, 26, 977-1003.

Koberg, C. S., Boss, R. W., Senjem, J. C., \& Goodman, E. A. (1999). Antecedents and outcomes of empowerment: empirical evidence from the health care industry. Group and Organization Management, 24, 71-91.

Konovsky, M. A., \& Cropanzano, R. (1991). Perceived fairness of employee drug testing as a predictor of employee attitudes and job performance. Journal of Applied Psychology, 76, 698-707.

Kozlowski, S. W. J., Chao, G. T., Smith, E. M., \& Hedlund, J. (1993). Organizational downsizing: strategies, interventions, and research implications. In C. L. Cooper, \& I. T. Robertson (Eds.), International review of industrial and organizational psychology, (Vol. 8, pp. 263-332). New York: Wiley.

Kraimer, M. L., Seibert, S. E., \& Liden, R. C. (1999). Psychological empowerment as a multidimensional construct: a test of construct validity. Educational and Psychological Measurement, 59, 127-142.

Lazarus, R. S., \& Folkman, S. (1984). Stress, appraisal, and coping. New York: Springer.

Lee, T. W., \& Maurer, S. (1999). The effects of family structure on organizational commitment, intention to leave, and voluntary turnover. Journal of Managerial Issues, 11, 493-513.

Lee, T. W., \& Mitchell, T. R. (1994). An alternative approach: the unfolding model of voluntary employee turnover. Academy of Management Review, 19, 51-89.

Lee, T. W., \& Mowday, R. T. (1987). Voluntarily leaving an organization: an empirical investigation of Steers and Mowday's Model of Turnover. Academy of Management Journal, 30, 721-743.

Lewis, J. D., \& Weigert, A. (1985). Trust as a social reality. Social Forces, 63, 967-985.

Lind, E. A., \& Tyler, T. R. (1988). The social psychology of procedural justice. New York: Plenum Press.

Luhmann, N. (1979). Trust and power. New York: Wiley.

Mathieu, J. E., \& Zajac, D. M. (1990). A review and meta-analysis of the antecedents, correlates, and consequences of organizational commitment. Psychological Bulletin, 108, 171-194.

Mayer, R. C., \& Schoorman, F. D. (1992). Predicting participation and production outcomes through a twodimensional model of organizational commitment. Academy of Management Journal, 35, 671-684.

Mayer, R. C., \& Schoorman, F. D. (1998). Differentiating antecedents of organizational commitment. Journal of Organizational Behavior, 19, 15-28.

Mayer, R. C., Davis, J. H., \& Schoorman, F. D. (1995). An integrative model of organizational trust. Academy of Management Review, 20, 709-734.

Mishra, A. K. (1996). Organizational responses to crisis: the centrality of trust. In R. M. Kramer, \& T. R. Tyler (Eds.), Trust in organizations: Frontiers of theory and research (pp. 261-287). Thousand Oaks, CA: Sage.

Mishra, A. K., \& Mishra, K. E. (1994). The role of mutual trust in effective downsizing strategies. Human Resource Management, 33, 261-279.

Mishra, A. K., \& Spreitzer, G. M. (1998). Explaining how survivors respond to downsizing: the roles of trust, empowerment, justice, and work redesign. Academy of Management Review, 23, 567-588.

Mishra, K., Spreitzer, G. M., \& Mishra, A. (1998). Preserving employee morale during downsizing. Sloan Management Review, 39, 83-95.

Mitchell, T. R., \& Lee, T. W. (2001). The unfolding model of voluntary turnover and job embeddedness: foundations for a comprehensive theory of attachment. Research in Organizational Behavior, 23, 198-246.

Mobley, W. (1977). Intermediate linkages in the relationship between job satisfaction and employee turnover. Journal of Applied Psychology, 62, 237-240.

Morrison, E. W., \& Phelps, C. C. (1999). Taking charge at work: extra-role efforts to initiating workplace change. Academy of Management Journal, 42, 403-419.

Mowday, R., Steers, R., \& Porter, L. W. (1979). The measurement of organizational commitment. Journal of Vocational Behavior, 14, 224-247.

Mowday, R., Steers, R., \& Porter, L. W. (1982). Organizational linkages: the psychology of commitment, absenteeism, and turnover. San Diego, CA: Academic Press. 
Niehoff, B. P., \& Moorman, R. H. (1993). Justice as a mediator of the relationship between methods of monitoring and organizational citizenship behavior. Academy of Management Journal, 36, 527-556.

Niehoff, B. P., Moorman, R. H., Blakely, G., \& Fuller, J. (2001). The influence of empowerment and job enrichment on employee loyalty in a downsizing environment. Group \& Organization Management, 26, 93 112.

O’Neill, H. M., \& Lenn, D. J. (1995). Voices of survivors: words that downsizing CEOs should hear. Academy of Management Executive, 9, 23-33.

Parker, S. K., \& Spriggs, C. A. (1999). Minimizing strain and maximizing learning: the role of job demands, job control, and proactive personality. Journal of Applied Psychology, 84, 925-393.

Pillai, R., Schriesheim, C., \& Williams, E. (1999). Fairness perceptions and trust as mediators for transformational and transactional leadership: a two-study sample. Journal of Management, 25, 897-933.

Reichheld, F. F. (2001). Loyalty rules! How today's leaders build lasting relationships. Cambridge, MA: Harvard Business School Press.

Robinson, S. L., \& Rousseau, D. M. (1994). Violating the psychological contract: not the exception but the norm. Journal of Organizational Behavior, 15, 245-259.

Rousseau, D. M. (1995). Psychological contracts in organizations: Understanding written and unwritten agreement. Thousand Oaks, CA: Sage Publications.

Rousseau, D. M., \& Tijorilawa, S. (1999). What's a good reason to change? Motivated reasoning and social accounts in promoting organizational change. Journal of Applied Psychology, 84, 514-528.

Sitkin, S. B., \& Roth, N. L. (1993). Explaining the limited effectiveness of legalistic 'remedies' for trust/distrust. Organization Science, 4, 367-392.

Somers, M. J. (1995). Organizational commitment, turnover, and absenteeism: an examination of direct and interaction effects. Journal of Organizational Behavior, 16, 49-58.

Somers, M. J., \& Birnbaum, D. (1999). Survival versus traditional methodologies for studying turnover: Differences, divergences, and directions for future research. Journal of Organizational Behavior, 20, $273-284$.

Spector, P. (1986). Perceived control by employees: a meta-analysis of studies concerning autonomy and participation at work. Human Relations, 39, 1005-1016.

Spreitzer, G. M. (1995). Psychological empowerment in the workplace: dimensions, measurement, and validation. Academy of Management Journal, 38, 1442-1465.

Spreitzer, G. M., Kizilos, M., \& Nason, S. (1997). A dimensional analysis of the relationship between psychological empowerment and effectiveness, satisfaction, and strain. Journal of Management, 23, 679-704.

Staw, B. M., Sandelands, L. E., \& Dutton, J. E. (1981). Threat-rigidity effects in organizational behavior. Administrative Science Quarterly, 26, 501-524.

Tett, R. P., \& Meyer, J. P. (1993). Job satisfaction, organizational commitment, turnover intention, and turnover: path analyses based on meta-analytical findings. Personnel Psychology, 46, 259-277.

Thibaut, J., \& Walker, L. (1975). Procedural justice. New York: Wiley.

Thomas, K., \& Velthouse, B. (1990). Cognitive elements of empowerment: an 'interpretive' model of intrinsic task motivation. Academy of Management Review, 15, 666-681.

Tyler, T. R., \& Bies, R. J. (1990). Beyond formal procedures: the interpersonal context of procedural justice. In J. Carroll (Ed.), Applied social psychology and organizational settings (pp. 77-98). Hillsdale, NJ: Erlbaum.

Van Dyne, L., \& LePine, J. A. (1998). Helping and voice extra-role behaviors: evidence of construct and predictive validity. Academy of Management Journal, 41, 108-119.

Wall, T. D., Jackson, P. R., Mullarkey, S., \& Parker, S. K. (1996). The demands-control model of job strain: a more specific test. Journal of Occupational and Organizational Psychology, 69, 153-166.

Wiebe, D. J. (1991). Hardiness and stress moderation: a test of proposed mechanisms. Journal of Personality and Social Psychology, 60, 89-99.

Wu, V., \& Short, P. M. (1996). The relationship of empowerment to teacher job commitment and job satisfaction. Journal of Instructional Psychology, 23, 85-89.

Zand, D. E. (1972). Trust and managerial problem solving. Administrative Science Quarterly, 17, $229-239$. 


\section{Appendix}

\section{Distributive justice}

1. Separated* employees are being taken care of by the company.

2. This company is offering adequate assistance to separated employees in finding a new job.

3. This company is offering adequate severance pay to separated employees.

4. This company is doing the best that they can to ease the transition of separated employees.

\section{Procedural justice}

5. Decisions on who is going to be separated are being made in an unbiased manner.

6. The criteria for employee separations are fair and being applied consistently across employees.

7. Employees who are separated will receive adequate advance notice.

\section{Interactional justice}

8. Site management collected accurate and complete information before making the decision to consolidate.*

9. Site management clarified the decision to consolidate, providing additional information when requested.

10. Site management offered adequate justification for the consolidation decision.

11. Site management explained very clearly the consolidation decision that has been made.

12. The implications of the consolidation decision were discussed with me.

\footnotetext{
*The use of the words 'separated employees' for survivors and 'consolidation' for downsizing, were based on the language used by the organization we studied. To avoid confusion, we used their language. But there were no other separated employees at the time of the downsizing nor were other related activities (like business divestitures) conducted during the time of the consolidation. Moreover, it was very clear to employees that the questionnaire was being administered to get their assessment how the downsizing activity was being handled.
} 